\title{
Virtual USATIC: A totally on-line conference to share good practices and experiences using ICT on Higher Education
}

\author{
Alejandre Marco, José Luis ; Allueva Pinilla, Ana Isabel ${ }^{a}$; Lozano Albalate, María \\ Teresa $^{b}$ and Trillo-Lado, Raquel ${ }^{c}$ \\ ${ }^{\mathrm{a}}$ Applied Mathematics, ${ }^{\mathrm{b}}$ Centro Universitario de la Defensa ${ }^{\mathrm{c}}$ Computer Science and \\ Systems Engineering, Red EuLES, U. de Zaragoza, Spain.
}

\begin{abstract}
During the last decades, the use of virtual environments and platforms to leverage the learning-teaching processes has increased enormously. However, there exist few virtual initiatives to discuss and promote good practices on these environtments. This paper presents the initiative Virtual USATIC (Ubicuo y Social: Aprendizaje con TIC), a conference with a totally virtual format, whose main goal is to provide a virtual environment where people involved in higher education (students, professors, etc.) can share and discuss their experiences about the use of Information and Communication Technologies in learning processes. Moreover, the conference also promotes the participation of the attendants to on-line tutorials, courses and virtual training workshops on specific topics (Digital Right Managements of material, Accesability and Usuability of materials, etc.) where all participants can learn and experience on issues related to the conference. This iniciative started on June 2013 and has been repeated every year since then. So, different parameters to evaluate its evolution and success are described along.
\end{abstract}

Keywords: Virtual Conferences and Learning Environments; Social Media ELearning; High Education with ICT. 


\section{Introduction}

During the last decades, new business models and changes in society are arising due to the constant evolution of Information and Communication Technologies (ICT). Thus, for example, traditional post mail has been almost substituted by e-mails. Learning processes and systems should also change in order to be more efficient, take advantage of ICT and be adapted to this new context, usually called Information Society.

With this idea in mind, a group of teachers of the University of Zaragoza decided in 2013 to organize a conference named Virtual USATIC (Ubicuo y Social: Aprendizaje con TIC; Ubiquitous and Social Learning with ICT, http://www.virtualusatic.org/.). The main purpose of this conference is providing a work environment to promote experiences to improve the quality of teaching by means of sharing information, ideas, knowledge, research results and teaching experiences among the community involved and interested in learning processes supported by ICT, in particular, professionals in the field of higher education whose instructional language was Spanish. In addition, the conference has enabled the training of teachers through the organization of virtual workshops on ICT tools.

Moreover, we decided to beg for a completely virtual event developed in the virtual platform CourseSites to increase the participation and to reduce the costs of attendace. Moreover, the participation in the conference is open access and free, if certification is not desired. So, it allows exchange, while it offers the possibility of training in strategic topics of professional development, as we currently understand learning: ubiquitous and social.

The rest of the paper is organized as follows. In Section 2, some information about the Red EuLES, the organizer, is depicted. The structure of Virtual USATIC is described in detail in Section 3. In Section 4, analytics about the participants in the different editions of the conference are shown. Then, in Section 5, results of the surveys are presented. Finally, in Section 6, conclusions and future work are presented.

\section{About Red EuLES}

Virtual USATIC is a virtual conference organized by Red EuLES (http://eules.unizar.es), an interdisciplinary educational research network in uLearning environments in higher education. The Red EuLES' objectives are the interaction, cooperation and transfer of knowledge and technology and the exchange of experiences and resources among the educational community, in relation to uLearning environments in a higher education level. We understand this model in its extensive and opened meaning, and unifying the different evolutions of the learning process combined with the latest technology trends, ranging from bLearning models (Blended Learning) through eLearning (Electronic Learning), mLearning (Mobile Learning) and Web 2.0, until arising the concept of ubiquity that allows us to take the teaching-learning process at any time, place and situation. At the same time, Red 
EuLES contributes to increase the visibility of the participant institutions and thus to collaboratively create and share knowledge to improve teaching quality.

This network, promoted and financed by Cátedra Banco Santander (U. of Zaragoza, Spain), has been recognized as an Interdisciplinary Network of the U. of Zaragoza since 2010.

\section{Structure of the Conference}

The duration of the conference was 5-days in the first edition and 4-days in the rest of editions celebrated so far. In particular, the conferences lasted from monday to thursday (to friday in the first edition) and each day was dedicated to a particular topic related to Ubiquitous and Social Learning. Concretely, these topics have been: 1) Learning platforms and environments, 2) Materials and Resources, 3) Tools 2.0, and 4) Social networks and uLearning.

The first event each day was a plenary session, moderated by two members of the organization, where a guest speaker gives a keynote; e.g., those of last edition were:

1. How is the digital transformation of universities impacting on educational innovation? $\mathrm{M}^{\mathrm{a}}$ del Carmen Romero Ternero, Director of the Digital Strategy Secretariat of the Digital Development and Evaluation Vicerrectorado at the Universidad de Sevilla, Spain.

2. Towards a new school. Toni Solano, Language and Literature teacher and ICT trainer at the Secondary School Bobalar, Castellón de la Plana, Spain.

3. WEB 2.0 tools: from substitution to transformation. Santiago Campión, teacher in the area Didactics and School Organization at the Universidad de La Rioja, Spain.

4. Dissemination of knowledge as a form of learning. Clara Isabel Grima Ruíz, Applied Mathematics Professor at the Universidad de Sevilla, Spain.

After that, participants were available to discuss, in forums, about several works (submissions and posters) previously selected in a revision process. Experts in the subject energized the forums, to leverage the interaction and discussion among participants.

On the same platform, training workshops were developed. They were eminently practical and required an average commitment of 10 hours, which each participant may perform over the duration of the workshops. As an example, the training workshops of last edition were:

1. Build your Educational Website with Google Sites

2. Intellectual Property and Licensing of Contents

3. QR Code: How to Use them in Teaching

4. How to Easily Create Educational Video Tutorials with ScreenCast-o-Matic

5. How to Use YouTube to Post and Manage your Educational Videos

6. Open Educational Resources (OER): what are they? and how to use them? 
7. Designing Forms and Online Surveys with Google

8. Forms Answers Management and Administration and Online Surveys with Google After each edition of the conference, the proceedings have been published in digital format with an ISBN, including every submission and poster presented. This publication is free access for all the speakers and the last ones had an extension of 800 pages. Besides, in 2015 edition, selected papers were invited to write a book chapter. The Cátedra Banco Santander of the U. of Zaragoza, with the publisher Prensas Universitarias de la U. de Zaragoza, published the complete book in a special issue in paper (Allueva Pinilla \& Alejandre Marco, 2016).

\section{Participation in the Different Editions}

In the first edition of the conference celebrated in June 2013, there were 340 people attending, 55 of them presented their works to be discussed in the forums. In the following edition, in June 2014, more than 550 people attended and could debate and discuss the content of more than 160 accepted papers and posters. In June 2015, 708 attendants participated in the conference and 290 of them presented a communication or poster. In the last edition celebrated so far (in June 2016), 498 attendants participated in the conference and 246 of them presented a communication or poster (see Figure 1 and Figure 2).

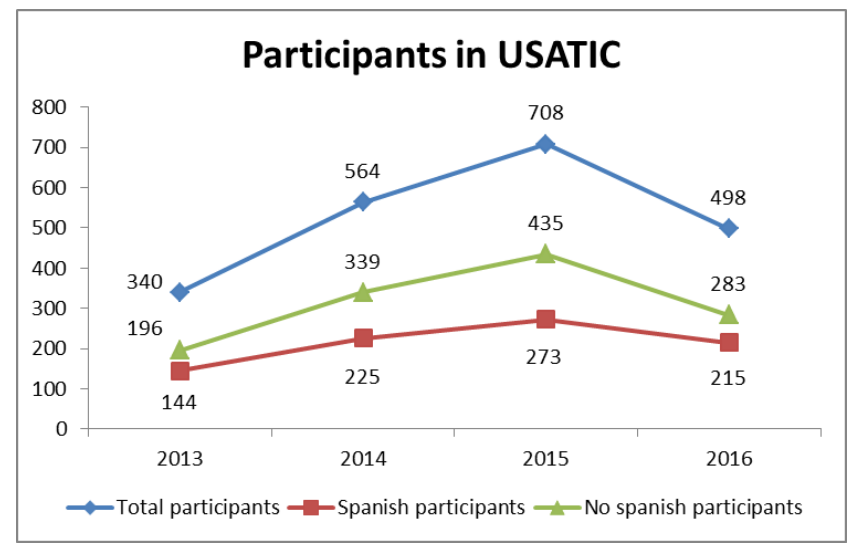

Figure 1. Participants in the different editions of the Virtual USATIC conference. Source: own (2016).

We would like to highlight that there has been a large number of authors who have participated in several editions of the conference, as we think it represents the idea that participants consider that the conference is really interesting. In addition, only around 50\% of the authors pay a small fee to receive a certificate.

Finally, Figure 3 shows the number of communications and posters presented in the different editions, and Figure 4, the amount of contributions grouped by topics. 


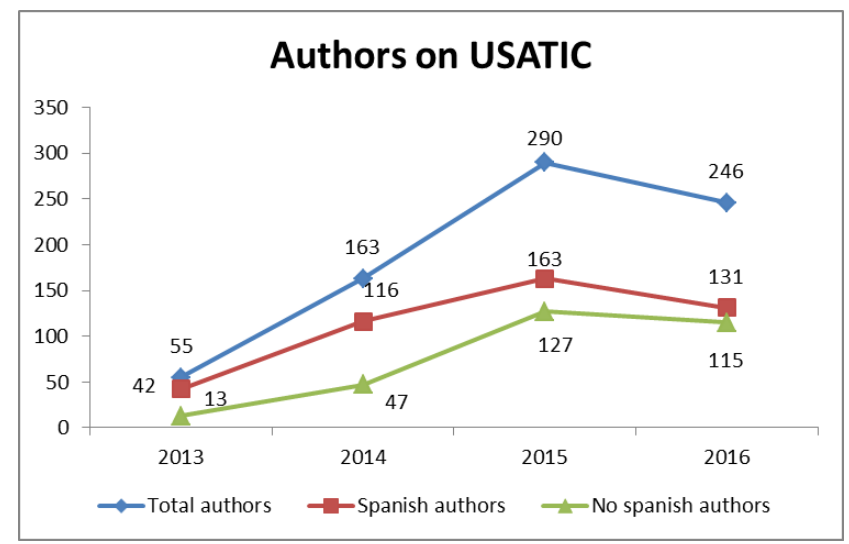

Figure 2. Authors in the different editions of the Virtual USATIC conference. Source: own (2016).

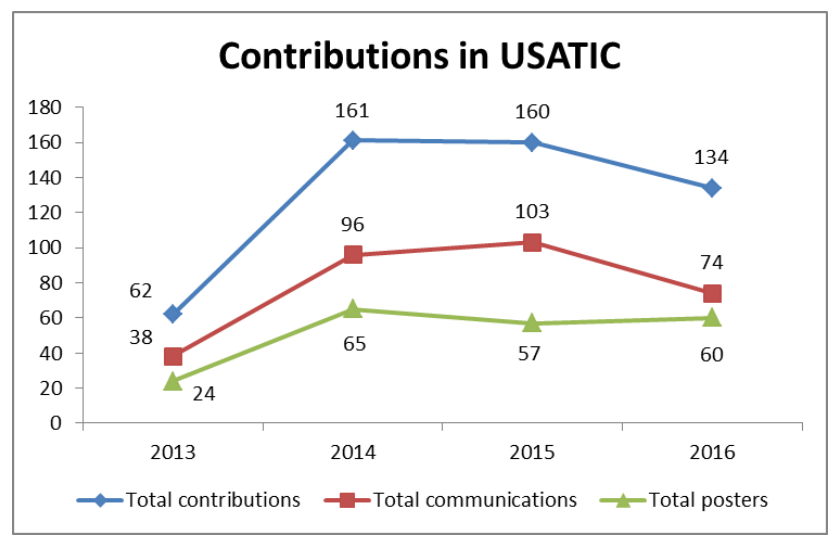

Figure 3. Contributions in the different editions of the Virtual USATIC conference. Source: own (2016).

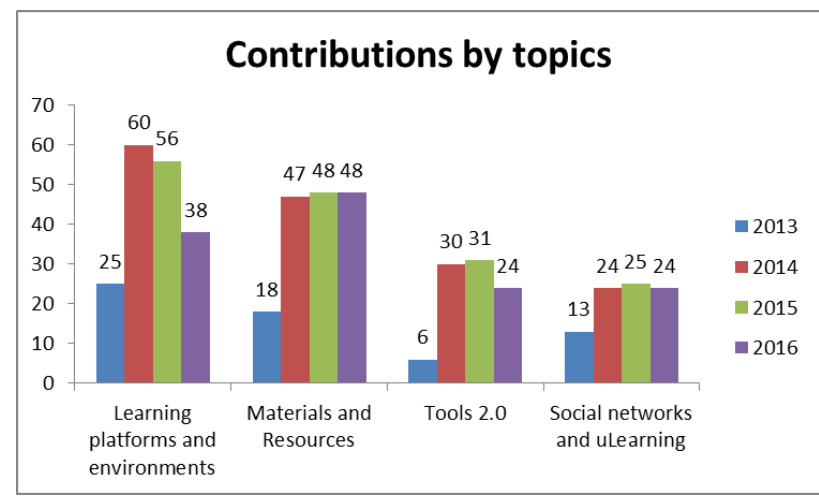

Figure 4. Contributions by topics in the different editions of the Virtual USATIC conference. Source: own (2016). 
The number of countries where attendants come from is also representative: in 2013, 17 different countries were represented; in 2014, 24; in 2015, 21; and in 2016, 23. The 32 countries represented so far in the conference were: Argentina, Australia, Bolivia, Brasil, Canada, Chile, Colombia, Costa Rica, Cuba, Ecuador, El Salvador, España, Germany, Guatemala, Honduras, Italia, México, Nicaragua, Panamá, Paraguay, Perú, Poland, Portugal, Puerto Rico, The Netherlands, United Kingdom, República Dominicana, Sweden, Switzerland, United States, Uruguay and Venezuela.

\section{Participants' Satisfaction Survey}

Participants were asked to fill in a final satisfaction survey, and 390 of them did it. Results provided were similar in all performances. Here we present results on the key issues of the last edition. We also focus on results provided by those participants attending the last two editions (both) and we will name them as "repeat participants".

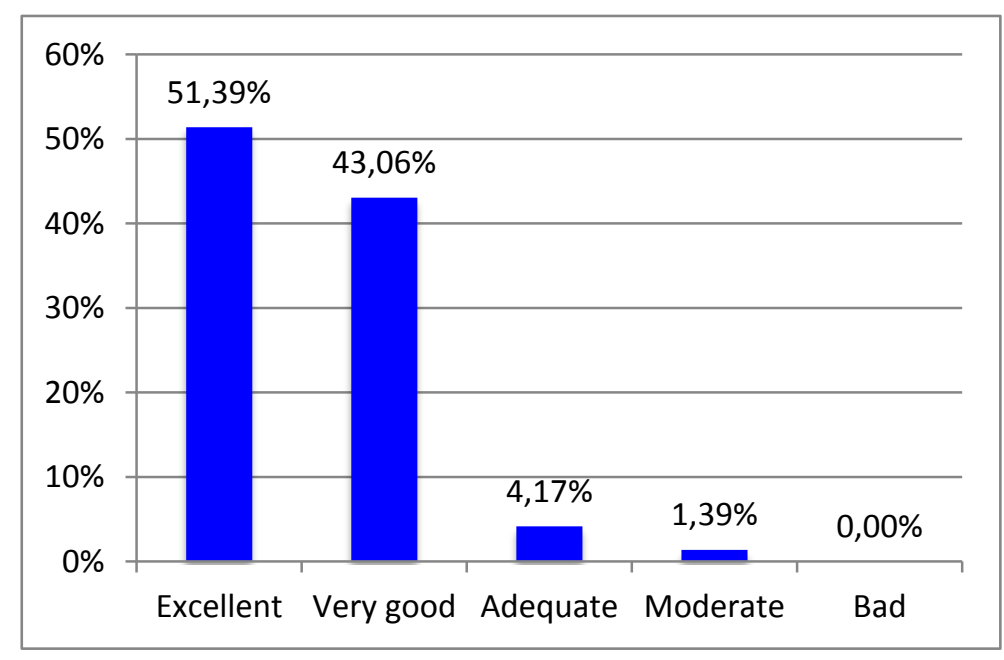

Figure 5. Overall assessment of the Virtual USATIC conference. Source: own (2016).

Figure 5 shows that the overall assessment of $94,45 \%$ of participants answer is excellent or very good. The percentage increases to $96 \%$ in repeat participants.

In Figure 6, results on review issues related to the content of the conference are presented. Participants were asked about: quality of the information contents, structuring information, content fragmentation, information volume and relevance of conference topics. Results are also mainly excellent or very good. Besides, the answer to the question: Was the conference useful (very much - less - nothing)?, 92\% answered very much and no one nothing. In addition, nearly $100 \%$ of repeat participants answered very much to this question. Moreover, the degree of satisfaction with respect to the degree of learning of all participants is $100 \%$ very satisfied or fairly satisfied, around $50 \%$ each one of these options. 


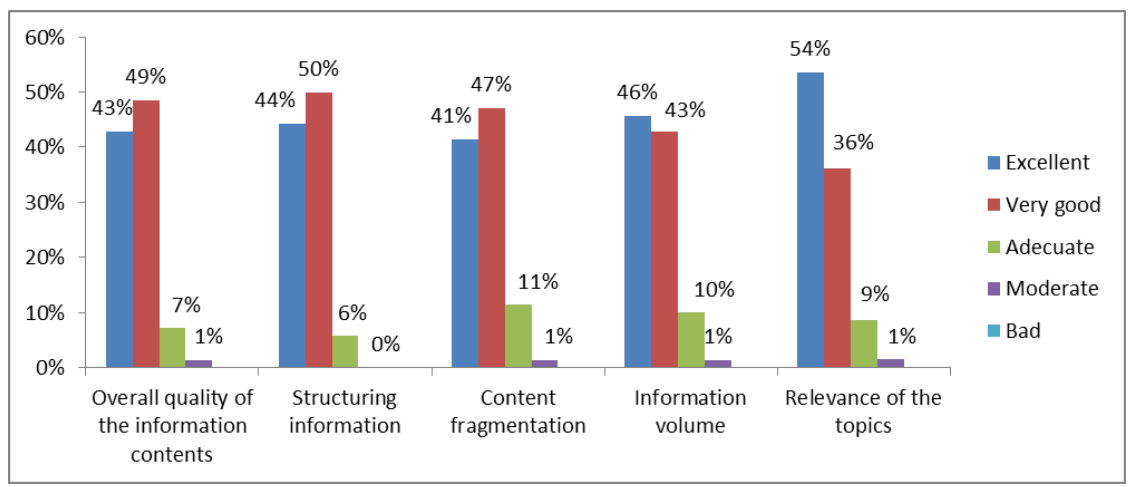

Figure 6. Review issues related to the contect of the Virtual USATIC conference. Source: own (2016).

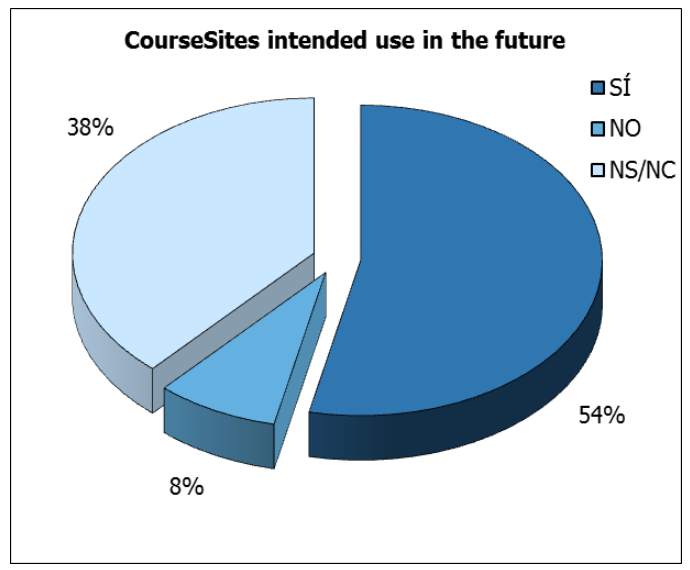

Figure 7. Intended use in the future of the Coursesites platform. Source: own (2016).

In relation to the eLearning platform used, CourseSites, there was an overall satisfaction and $54 \%$ of participants said that they intended to use it again and only $8 \%$ of participants said that they would not use it in the future (Figure 7).

When participants were asked about how likely were them to recommend Virtual USATIC to a colleague or a friend, practically all of them (98\%) answered YES, I recommend the conference. Finally, practically all of them (99\%) said YES I would like to participate in a new edition of Virtual USATIC conference. Regarding the results obtained on the satisfaction of participating in training workshops, a brief set of results on assessment of the overall quality of workshops and assessment of quality of contents (rated from 1 to 10), is presented (Figure 8). Results express the high degree of satisfaction with the training received in workshops (descrived in Section 3). The score was excellent (9 or 10 points) in more than $70 \%$ of cases and there was no score lower than 6 . 


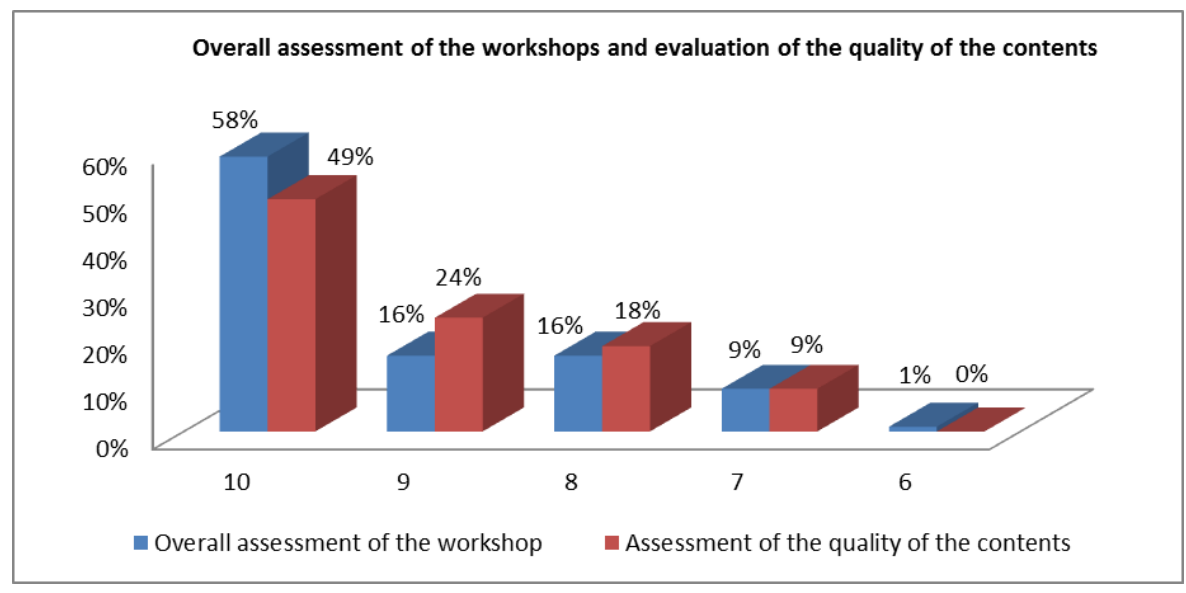

Figure 8. Overall assessment of workshops and evaluation of the quality of contents. Source: own (2016).

A final consideration that may be relevant in the analysis (apart from those relating to satisfaction) is how respondents said that they obtained information on the conference for the first time (can be several): by email (50\%), informed by their institution $(22 \%)$, a colleague or friend informed them (37\%), through social networks and website (10\%).

\section{Conclusions and future work}

Results obtained so far are good. Many people already know and have participated in the conference. Also, many countries were represented (32 in total). Moreover, the participants that filled the surveys are satisfied. Thus, in the last edition, 94,45\% of participants answered that the overall assessment of the conference was excellent or very good, and 92\% answered that the conference was very useful. Moreover, almost all of them (98\%) said that they were going to recommend Virtual USATIC and that they would like to participate in a new edition (99\%). Satisfaction with the training received at the workshops has also been very high. So, we plan to continue organizing this conference next years.

Main goals for next years are consolidating this community exchange, number of participants and submissions, as well as increasing workshop educational opportunities.

\section{Aknowledgements}

We would like to thank all institutions and companies supporting Virtual USATIC.

\section{References}

Allueva Pinilla, A. I., \& Alejandre Marco, J. L. (2016). Simbiosis del aprendizaje con las tecnologías. Experiencias innovadoras en el ámbito hispano. Zaragoza: Prensas de la Universidad de Zaragoza. 